V.V.Sobolev, Dr. Sc. (Tech.), Prof., orcid.org/0000-0003-1351-6674,

National Mining University, Dnipro, Ukraine, e-mail: N. V. Bilan, Cand. Sc. (Geol.), Assoc. Prof., orcid.org/0000-0002-4086-7827

\title{
PHYSICAL CONDITIONS OF THE 'LIGHT' CORE FORMATION AND THERMONUCLEAR HEAT SOURCE DEEP INSIDE THE EARTH
}

Purpose. Experimental research into the physical model of the Earth's core formation in the center of gas-dust spiral vortex and numerical assessment of the physical conditions associated with the development of thermonuclear reactions in the Earth's core.

Methodology. Analysis of the main points of conventional conceptions, their principal merits and drawbacks which delineate their potential possibilities. Experimental studies implementing shock-wave treatment of porous materials in cylindrical containers. Numerical assessment of the physical conditions that initiate thermonuclear reactions in the Earth's core.

Findings. It is extremely important to choose the model of the Earth formation with originally "light" core for several reasons. First, it provides a physically grounded mechanism of the thermonuclear heat source formation; second, the process of the Earth transition to equilibrium state inevitably creates conditions for mechanical, physical and chemical activity of elements in geospheres. Numerical assessment was performed to estimate the main conditions which are necessary for thermonuclear heating of the Earth's central bulk - to determine the deuterium nuclei concentration and the respective temperatures.

Originality. The authors suggested a model describing formation of the initially "light" core of the Earth. Experiments allowed studying some physical peculiarities of spiral vortices initiation and development. Regularities of change in plasma parameters, core temperature and thermonuclear energy release have been established in reference to the Earth's age.

Practical value. The obtained results will be useful for studying such important planetary geological phenomena as matter differentiation and formation of spheres inside the planet, as well as heat flow distribution in its bulk.

Keywords: gas and dust matter, spiral vortex, the Earth's core, thermonuclear reactions, the Earth's age

Introduction. The origin and evolution of stellarplanetary systems, the Solar System in particular, is one of the oldest unsolved problems of cosmogony, the fundamental base of nature cognition. Research into the mechanism of the Earth formation and peculiarities of its structure, chemical composition and distribution of elements in geospheres, their mechanical, physical and chemical properties, probable heat source deep inside the Earth - constitutes an important aspect of human culture. The interest of science is stimulated by a natural desire to apply the obtained knowledge to the prognostic assessment of the probable scenario of the Earth's evolution and the ways of terrestrial civilization efficient development causing minimum damage to the environment.

In geosciences, one of the most important lines of research is related to the investigation of the Earth's core formation, as well as physical and chemical processes in it. As a rule, modeling experiments help to analyze the possible reasons and mechanisms lying behind the formation of gas-dust spiral structure in the attempt to prove universal character of the star formation in central bulges of spiral vortices, planet and satellite formation in their arms.

Research into the Earth's origin comprises two main essentially different and competing models which envisage the initial formation of "light" or "heavy" core, cold or hot Earth, respectively, and the physical conditions which allow for shaping of such characteristics.

(C) Sobolev V. V., Bilan N. V., 2018
Furthermore, the models differently interpret the Earth's history, geological processes, chemical composition of the core, specifics of chemical elements' distribution in geospheres, and so forth. Understanding the mechanism of the Solar System formation is directly related to peculiarities of its evolution, prediction of possible risks and perspectives of creating living conditions acceptable for humans beyond the Earth's boundaries.

Among the most cutting-edge problems of the modern natural science is modeling of gas-dust protosolar cloud evolution, recreating scenario which describes the origin of the sun, planets, the Earth's core and its chemical composition, probable heat sources and heat distribution in geospheres. Different physical conditions of the Earth origin, described in the two above-mentioned models, predetermine essential difference in such critical planetary geological phenomena as matter differentiation and formation of spheres inside the planet. The choice and modernization of one of the Solar System origin conceptions bring us closer to the solution of the key geological problems.

Brief analysis of the key Solar System formation hypotheses. In the general algorithm of the Solar System formation and evolution, there is no place for any occasional or unique occurrences. The main stages preceding the Solar System emergence are concerned with the formation of gas-dust nebula and its acquiring the only stable form of motion - spiral vortex. On the whole, the history of gas-dust nebula origin and its evolution is 
the evidence of the gradual transition of a physical system to the stable form of existence.

Descartes' R. idea about vortex motion of protosolar cold matter turned so productive that, with different improvements, it became the foundation of many hypotheses. The most valuable part of I. Kant's hypothesis is concerned with the supposition about simultaneous formation of the sun and the planets. V. Fesenkov (1953), F. Hoyle (1958), A. Cameron (1962) and others suggested that the Sun and the planets were formed simultaneously from the cold gas-dust nebula in the joint process of evolution. One of the principal modern conceptions of the Solar System formation reads that the Earth was formed from the cold protoplanetary matter in the state of spiral-vortex motion. This group of hypotheses suggests that the Earth heating occurred due to the radioactive elements disintegration and conversion of the gravitational compression energy into heat.

The second group of hypotheses departs from the idea that the Earth was formed from the protoplanetary matter heated to approximately $30 \mathrm{kK}$, i.e. to the state of the "cold" plasma [1]. According to Laplace hypothesis, the protoplanetary nebula matter was incandescent. Thermal and kinetic energy of protoplanetary matter, including the heat of radioactive decay, stimulated its lamination inside spheres with subsequent differentiation. One of the scenarios envisages gravitational compression of the nebula formed from the remains of the supernova and the appearance of vortex protosolar cloud.

In 1982, N. Shilo put forward a hypothesis of the Solar System formation from the matter of vortex thermoplasma cloud [2]. It was in the arms of the main spiral (first order spiral) where plasma vortices of the second order were formed giving birth to planets. Planets' satellites were formed in the third order spirals. The spiral vortex is characterized by different angular rate of the spiral core rotation and rotation of its arms. This peculiarity eliminates the contradiction between mass distribution and the angular momentum. Thus, initial differentiation of protoplanetary matter has received a satisfactory explanation. Among physical properties of the protoplanetary plasma-gas medium dynamics, we should mention Coulomb forces and their key role in planets' formation.

The scholars who have recently suggested physical models of the Solar System formation share a critically important view on the physical mechanism of the Sun, planets and their satellites formation. According to this approach, all the bodies in the Solar System were formed in a single process from an individual dust-gas cloud. Major cosmogonist hypotheses generally reflect evolutionist ideas about the Sun and planets formation as a physical system whose creation is determined by a number of regularities. Accumulation of experimental data related to the Solar System research; discovery and observation of other planetary systems; new achievements in cosmogony, geology, geochemistry, celestial mechanics and physics allowed picturing the Sun and planets formation from the evolutionist perspective as a regular process of stellar systems formation in the Universe.
Scientists from Lawrence Livermore National Laboratory (University of California), geologists from University of Illinois Urbana-Champaign, from New Mexico Institute of Mining and Technology in Socorro, University of Maryland in College Park and other US scientific centers; scholars from Vernadsky Institute of Geochemistry and Analytical Chemistry, the Schmidt Institute of Physics of the Earth affiliated with the Russian Academy of Sciences (IPE RAS) and other Russian institutes - are engaged in active research related to modeling the process of the Earth's core formation. We should also mention here the well known works by scientists from Liverpool University, Durham University and Oxford University. Professor Kei Hirose from Tokyo Institute of Technology is especially noted for his experimental research into micromodels of the Earth's core.

Despite the crucial importance of the problem under consideration for geological sciences, the mechanism of the core formation is still insufficiently studied. In the absence of accurate knowledge, there are only suppositions about the initial and the present day substance composition of the core. The modern science is lacking a credible theory of the Earth's core formation. Various existing assumptions based on the results of numerical modeling consider indirect geophysical, cosmic and chemical data. Lately, specialists from the University of Oxford have come up with the idea of uranium presence in the core composition [3]. Scholars from Hydrodynamics Institute (Russia) described their suppositions about the disintegration reaction of radioactive isotopes of uranium 235, plutonium 239 and potassium 40 in [4]. On the whole, hypotheses about the Earth's "heavy" core formation from the protoplanetary disc matter seem to be well-founded at first sight.

A radically different approach, which reads that the core composition included light components, such as hydrogen [5], hydrogen and helium [6], also appears reasonable enough. According to V. Larin's estimation (who incorporated Hoyle's ideas about magnetic separation of ionized particles and Shilo's hypothesis [2, 7] about thermoplasma state of the protoplanetary disc), the amount of hydrogen should have constituted $4.5 \%$ in terms of weight or more than a half $(59 \%)$ of all the planet's atoms. The core included iron, magnesium, silicon (together $-78 \%$ ), and other elements $-7.5 \%$. In [8], the authors investigate the Earth's core composition, analyze available experimental and geophysical data and make a conclusion that the outer liquid core has a homogeneous structure and density deficiency about $10 \%$; the inner core has a sufficiently heterogeneous structure with increased anisotropy of seismic waves, as discussed earlier in [1,9]. In the latter case, the density deficiency is about $5 \%$; according to the experimental data, such structure is in keeping with the properties of Fe-carbides. As far as light elements are concerned, these most probably would be silicon and oxygen.

Recently specified data testify that the core density is almost $10 \%$ less than the previously found value for the iron-nickel alloy. These data can be treated as the evi- 
dence of light elements presence in the core's composition. Indeed, of late there have been quite a few publications about the possible presence of sulfur, hydrogen, helium, carbon, oxygen, silicon, phosphorus, nitrogen etc. in the core. If it really contains any of the above listed elements, the core should be much lighter than previously assumed. Thus, D. Pushcharovskyi wrote in [10] that "the presence of significant amount (up to 40 mole \%) of hydrogen in the core is quite possible, which reduces its density to the values agreeing with seismology data".

Objectives of the article. It is assumed that the Sun was formed from the light components (hydrogen, helium) of the dust-gas cloud center in the process of its spiral vortex motion. The Earth, with its "light" core comprising a great amount of light components (mostly hydrogen), was "born" in vortices of the second order. Departing from this, the objective of the present research is to experimentally study the flow of the matter with light components concentrating in the vortex center with the view to building a model of the probable mechanism of the planet (and its core) formation. It is necessary to assume here that the gradient of heavy elements distribution across the radius of the spiral-vortex protosolar disc is described by the same regularity as across the radius of the galaxy disc. Summing up the results of the research conducted in extragalactic astronomy, the authors of [11] established that "the relative share of heavy elements decreases in the central regions of galaxies spiral vortex structure and increases - in their periphery". The effect of radial gradient of light (or heavy) elements' presence was discovered experimentally in the study related to shock-wave treatment of different powder mixtures [12]. It is noteworthy that in the studies of large-scale [11] and micro-scale [13] vortex structures, the features of distribution of elements and microparticles are the same.

The concept of the "light" core containing hydrogen gives way to the discussion of the probable Earth's heat source resulting from nuclear processes. Hence, the second objective of the research is to conduct numerical assessment of the physical conditions ensuring the development of thermonuclear reactions in the Earth's core.

Materials and experimental technique. Regularities of liquid copper (with insertions of graphite microparticles) flow were studied by means of the technique described in [14]. The material under study was a mixture of copper micropowders (92 weight \%) and graphite (8 weight \%). The $200 \mathrm{~mm}$ long containers with the inner diameter of $5 \mathrm{~mm}$ and outer diameter of $20 \mathrm{~mm}$ were made of steel. A charge of explosive with $125 \mathrm{~mm}$ diameter was made of hexogen with the density $1.100 \mathrm{~kg} / \mathrm{m}^{3}$. The charge of light-sensitive explosive compound [15] was blasted by laser monoimpulse according to the procedure described in [14]. Pressure in the studied mixture was created as a result of compressing the container walls by the products of the charge detonation. The researchers employed a standard complex of metallophysical methods of investigation.

Research into the properties of spiral vortices. For the first time, we discovered the origination and develop- ment ofspiral and vortex flow of the material comprising the mixture of three components (graphite microparticles, liquid copper and gas) in the research related to the diamond synthesis by blasting in cylindrical containers, Fig. 1, $a$. The results of this work were presented in 1977, at the Conference on Creation and Application of Superhard Materials (Institute of Superhard Materials, Kyiv, Ukraine) and published in $[15,16]$. Before this publication, such effect of the matter spiral-vortex flow in cylindrical units subjected to shock-wave treatment had not been known.

Fig. 1, $b$ shows the cross-section of the container after shock-wave treatment. In the upper part of the container (area $L_{1}$ ), we have identified vortex flow in the material under study (Figs. $1, b, c$ ). Area $L_{2}$ refers to the flow which continues according to the spiral vortex scenario. It is interesting that there is a great external similarity between hydrodynamic flows in the microstructure of shocked porous materials and large-scale spiral vortex stellar and planetary systems in the Universe.

In order to confirm the spiral-vortex character of the flow, we have analyzed the configuration of the shock wave in the materials under study and the flow character beyond the container. The shocked material was freely released through the open bottom of the container 3 , Fig. 2. We used a unit (Fig. 2, a), where the explosive charge 2 was blasted with the help of the layer of lightsensitive initiating substance BC-2 1 [15], excited by laser radiation according to the technique described in [14]. This method was used in order to prevent the possible asymmetrical propagation of detonation front in the charge BC-2. Impulse laser radiation initiated detonation across all the surface of the charge layer simultaneously. The resulting front of the detonation wave propagated from the top of the container 3 to its bottom perpendicular to the generatrix of the cylindrical container. Such scheme provided high repeatability and accuracy of the obtained results. Under the pressure of detonation products 9 , the container walls 3 are compressed, a shock wave, whose profile is shown in the picture and diagram (Fig. 2), is formed in the studied material.

By means of high-speed photorecording, we received a picture of the shock wave exit from the container bottom 3. The wave plane presents the so-called three-wave configuration: $A B-A A-A B$. Spatially, this wave is a truncated cone whose top $(\mathrm{A}-\mathrm{A})$ is a curvilinear front of the main (Mach) shock wave, Fig. 2, c. The pressure behind the Mach wave (A-A) front is 4-5 times higher than the pressure behind the front of inclined shock waves $\mathrm{A}-\mathrm{B}$. The mechanism of particles vortex motion origination behind the curvilinear front of the shock wave was analyzed according to the model in [16].

As a result of Mach wave front passage in the porous material, we obtain zone 7 , Fig. 2 , $c$, where, at the pressure of $(6 \ldots 7) \cdot 10^{10} \mathrm{~Pa}$ and the temperature of $0.3 \ldots 0.4 \mathrm{eV}$, the material viscosity is close to water viscosity. Molten copper and graphite particles motion acquires vortex character 8 . The material vortex thus formed moves towards the container bottom at the speed of $7.600 \mathrm{~m} / \mathrm{s}$. 


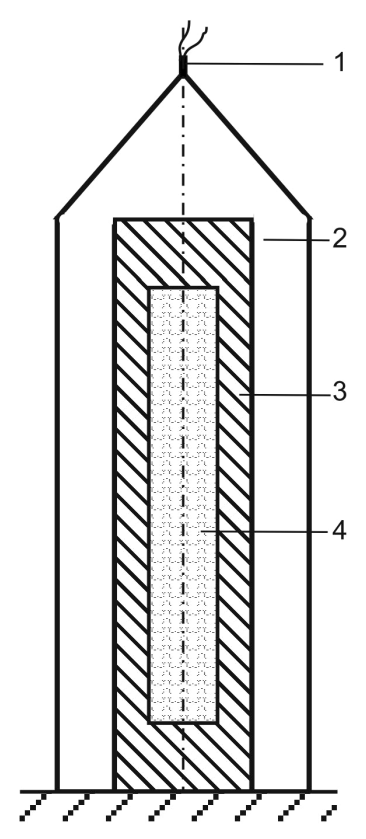

$a$
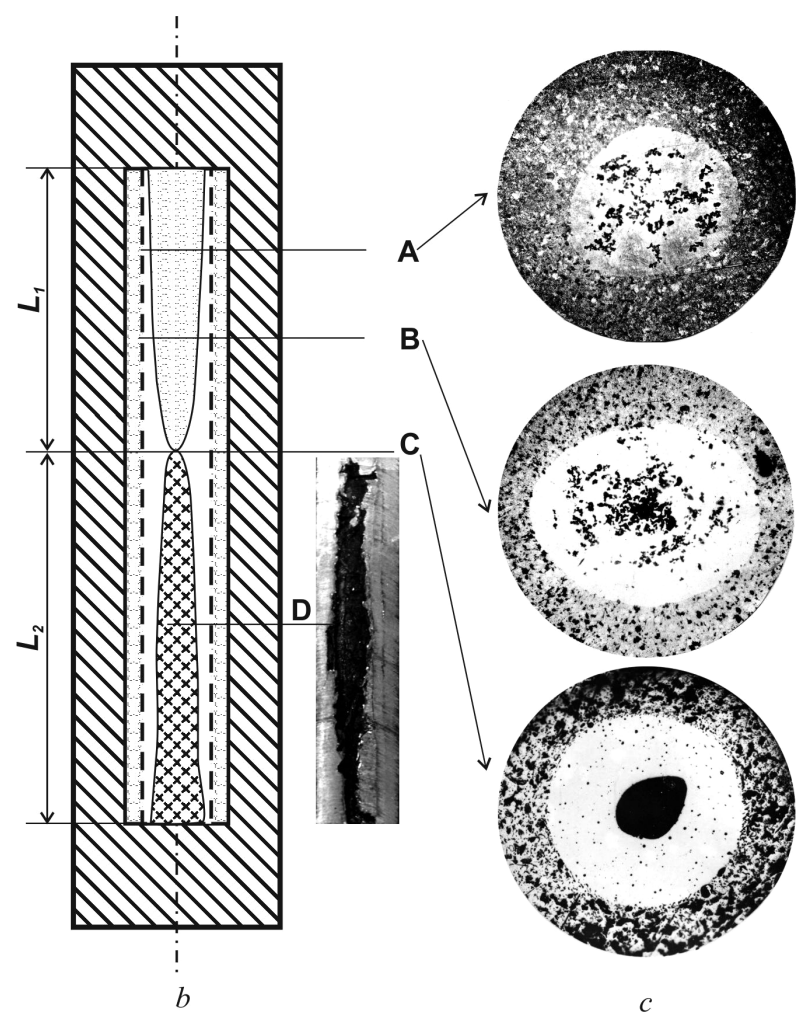

Fig. 1. Cylindrical container:

$a$-for shock-wave treatment of micropowders; $b$ - container (cross-section) after shock-wave treatment; $c$ - microstructures in sections $A, B, C ; D$-cross-section of area $L_{2} ; 1$-detonator; 2 - explosive; 3 - metallic container; 4 - mixture of copper and graphite microparticles

Under the impact of the shock wave inclined front (A$\mathrm{B})$, the porous material gets only compressed. The zones of compressed material 6 and liquid material 7 are separated by the surface of tangential discontinuity. On this surface, we witness stepwise change in the material viscosity.

Microstructure shown in Fig. 3 is the evidence of copper melting in zone 7 . Crystals oriented to the center testify to the cooling on the surface of the material compressed by the shock wave 2 .

We suggested that the spiral vortex flow of the molten copper will move towards the container bottom, exit it and leave the characteristic traces of the vortex flow on the target surface (Figs. 2, $d, e$ ). But it turned difficult to obtain the expected results because we had to select the

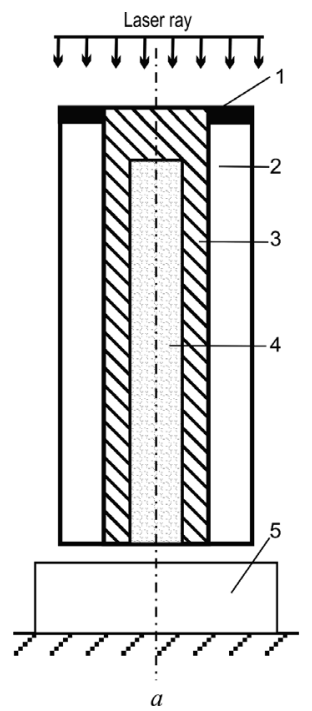

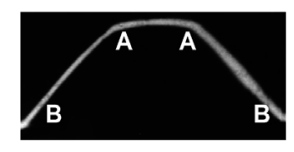

$b$

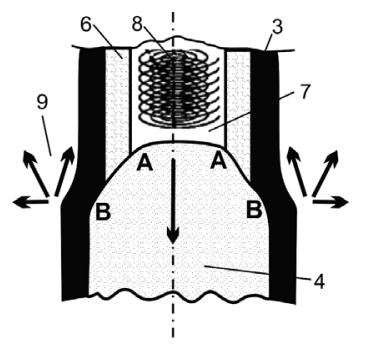

$c$
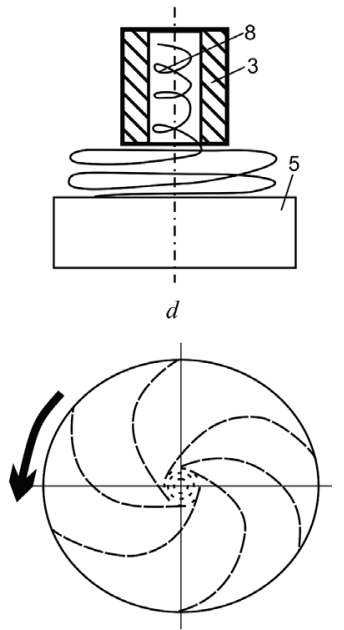

$e$

Fig. 2. Schematics of shock waves interaction:

$a$ - in the porous material placed in the cylindrical container; $b$ - Mach wave front in the studied material; $c$ - assumed scheme of the shock-wave process in the studied material; $d$ - scheme of the substance spiral vortex flow exiting the container; $e-$ traces of vortex flow made by the tossed material on the target 

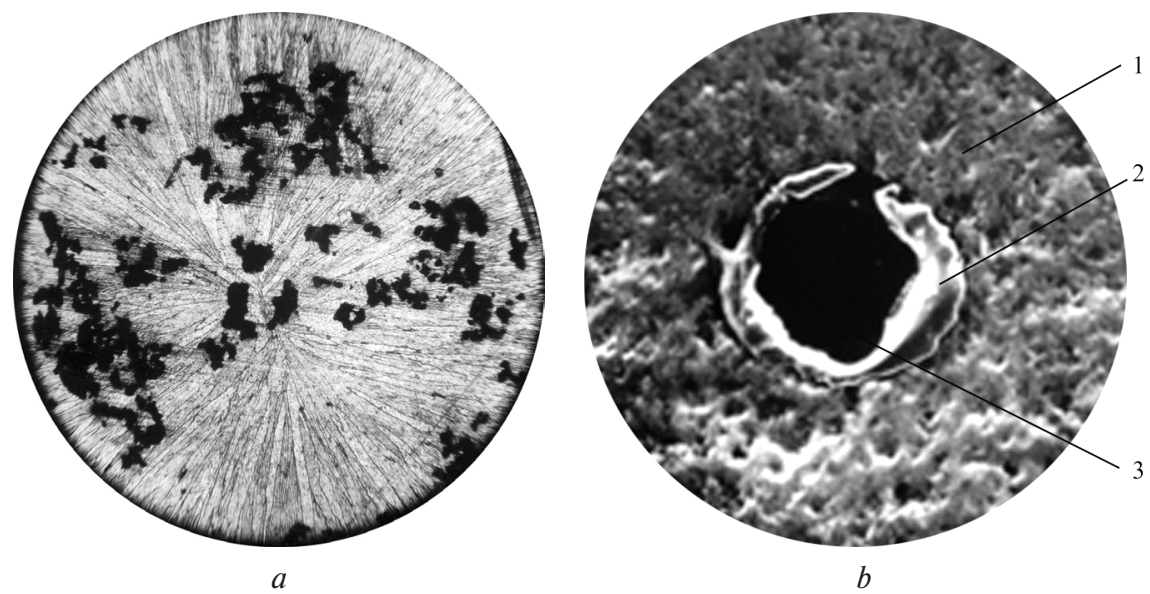

Fig. 3. Microstructure of the studied material after the passage of Mach wave front:

a-region L1, Fig. 1; b - region L2, Fig. 1; 1 - material treated by the inclined shock wave; 2 - part of solidified metal at the interface with the surface of tangential discontinuity; 3 - cavity formed near the container axis

necessary composition of the powders mixture, to make a preliminary assessment of the possible pressure and temperature ranges associated with the powders treatment, to choose the appropriate type of the explosive and to experimentally establish the size of the clearance $h$ (Fig. 2, $d$ ) between the container bottom and the target surface.

In the process of shock-wave treatment, the studied mixture is in extreme thermobaric conditions. When it abruptly moves from the container with cross-section of $50 \mathrm{~mm}^{2}$ into the space with infinite cross-section, the pressure changes likewise abruptly $\left(7 \cdot 10^{10} \rightarrow 10^{5} \mathrm{~Pa}\right)$, and the temperature drops dramatically from $3.300 \mathrm{~K}$ to the ambient values. Viscosity and other physical characteristics also change abruptly. When the material exits the zone with extreme characteristics, a coating of fast-quenched copper is formed on the target 5 surface. The traces of liquid metal vortex flow are left on the coating surface, Fig. 2, e. Unfortunately, we were not able to get a high quality photo of the vortex trace on the target surface.

The research into the character of the molten copper and graphite flow yielded the following results.

1. Spiral vortex character of the substance flow is the result of the impact produced by the shock wave curvilinear front on the mixture of microparticles (gas-dust material) (Figs. 2, b, c).

2. Spiral vortex, from the moment of its emergence and to the moment marking the beginning of graphite microparticles concentration in the vortex center, is characterized by the fine pitch of the spiral.

3. Components in the spiral vortex were distributed differentially: the lightest components coalesced in the center, while the heavier ones assembled closer to the periphery [12-14].

On the whole, the physical scenario of the matter spiral-vortex flow development and some peculiarities of its properties can be used to complement simulated ideas about the evolution of the protosolar spiral-vortex disc and protoplanetary vortices. The development of spiral-vortex flows and the characteristic properties in the case of microscopic dimensions (Fig. 1, c) and the case of protosolar disc scale in the model can be de- scribed in terms of the same scenario.

How can the obtained information contribute to the development of the Earth's core formation ideas? If we presumed that the mechanism of the Earth's formation in the spiral vortex center determines the future Earth's core formation specifics, we should admit that alongside with heavy components, there is a great amount of light elements (mostly hydrogen) in the core.

Light components agglomeration in the central region of the spiral vortex [11, 12] is one of its main features. The heaviest components of matter are clustering on the spirals which are farthest from the center, though on the whole the motion regularities and structural peculiarities of the vortex are not violated. The final stage of the vortex flow is characterized by the maximum concentration of light components in the vicinity of the rotation axis.

Thus, it is assumed that in the beginning, light elements (mostly hydrogen) in the center of the spiral protostellar vortex give birth to a star. Planets with "light" cores containing up to $4.5 \%$ hydrogen in terms of weight are formed on vortices' arms. The heaviest elements are partially dissipated in the mantle and are mostly concentrated in the Earth's crust. The amount of light components decreases, as the distance from the protostellar vortex center increases. It is probable that the planets formed on the periphery of the protostellar vortex have predominantly "heavy" cores.

It is critically important to select the model of the Earth with initially "light" core because the history of its development incorporates formation of a powerful inner heat source, convective transfer of matter deep inside the planet and particularly, physical and chemical activity of elements in geospheres.

Physical and mathematical model of the Earth's thermonuclear core. As a rule, the Earth's models consider several possible reasons for heat generation deep inside the planet: 1 - energy of radioactive elements' disintegration (not more than $15 \%$ of heating energy according to different assessment); 2 - gravitational differentiation of the mantle (maximum density of heat radiation approx. $9 \cdot 10^{10} \mathrm{erg} / \mathrm{g}$ ); 3 - Sun energy (heats only several meters of the Earth's crust) ; 4 - nuclear reactions in the 
Earth's core (the focus is on the possible reactions of synthesis [17] or nuclear fission [18]).

The ideas about nuclear processes in the Earth's core as one of the most probable sources of heat energy were developed in the works by V. Anisichkin, A. Bezborodov, A. Voitenko, A. Yershov, A. Solopova, I. Suslov, E. Terez, M. Fukuhara, P. K. Kuroda, R. B. Driscol, J. N. Nan$\mathrm{da}$, and many other scholars. Thus, one of the very first works [18] discusses the possibility of the thermonuclear heating of the Earth's central regions. The authors propose a technique for calculating parameters of several models of iron-hydrogen thermonuclear Earth's core. Several years later, an article [19] was published where the authors demonstrated that the main source of Earth energy is thermonuclear processes in the inner core. This paper presents supposition about the mechanism of heat energy transfer to the planet's surface which is hardly relevant. In his work [20], M. Fukuhara analyzes possible thermonuclear reactions yielding helium in the core and claims that heat generation results from threeparticle nuclear synthesis of deuterons. The authors of the cited and other, not less interesting, works do not propose physical models or present the results of numerical modeling. Assessments of the possible nuclear synthesis parameters are practically absent.

Experimentally obtained value of the density of the heat flow moving from the Earth's depth to its surface [21] is $\sim 5 \cdot 10^{-2} \mathrm{~W} / \mathrm{m}^{2}$. According to different sources, the value of the full heat flow through the Earth's surface is estimated at $(2.8 \ldots 3.1) \cdot 10^{13} \mathrm{~W}[20,22], 3.0 \times$ $\times 10^{13} \mathrm{~W}[23], 4.4 \cdot 10^{13} \mathrm{~W}[24], 4.6 \cdot 10^{13} \mathrm{~W}$ [25].

On the whole, the problem of the Earth's central regions heating has not been satisfactorily and finally solved yet. The possibility of simultaneous or subsequent impact of different heating processes cannot be excluded.

The task of the present research is to estimate the principal conditions that are necessary for thermonuclear heating of the Earth's central regions, namely: deuterium nuclei concentration and the range of the required initial temperatures. Another task was to identify the change of plasma parameters and thermonuclear energy radiation in respect to time. The research does not treat other important issues such as possible mechanisms of establishing the initial temperature ensuring the start of self-sustaining thermonuclear reaction.

The Earth model under study comprises an extremely heated thermonuclear core. The initial volume of the thermonuclear core for the sake of preciseness is presumed to equal $10^{-3}$ of the full Earth volume. Correspondingly, the initial radius of the thermonuclear core is $\sim 637 \mathrm{~km}$ ( 0.1 of the Earth mean radius). As the core is heated further, its radius increases.

The idea that there is a thermonuclear reactor in the Earth's central regions is not something extraordinary. The Sun and other stars, which are commonly considered to be thermonuclear reactors, belong to this type of objects.

Given high temperature and great plasma density of thermonuclear core, heat exchange in it is radiant and the optical thickness of the core is great. Rosseland ra- diation mean free path is considerably smaller than the core dimensions. Non-linear character of the radiant heat conductivity results in the fact that the temperature profile is close to plateau depending on the radius, which means that inside the core, the temperature gradient is not big and the temperature decreases abruptly only on its boundary [26]. Departing from this, while building a computational model, we allowed a simplification that the temperature is the same anywhere inside the thermonuclear core. For the same reason, processes in the thermonuclear core are treated as adiabatic, without heat exchange with the surrounding medium. In calculation, the pressure within the boundaries of the Earth's thermonuclear core was assumed equal to the pressure in the Earth center $p=3.92 \cdot 10^{11} \mathrm{~Pa}$ [21].

Let us estimate the actual range of the necessary and possible temperatures on the basis of the following considerations. Lower limit of the temperature range is defined by the fact that thermonuclear reactions are not intense at low temperatures and the emitted energy can be neglected. The upper range limit is determined by the fact that at high temperatures, the release of energy becomes colossal, i.e. the very fact of the Earth existence during $\sim 4.5$ billion years allows estimating the upper limit of the possible initial temperatures.

The equation of plasma state in thermonuclear zone is taken in the form

$$
p=\left(n_{\mathrm{Fe}}(1+i) n_{\mathrm{H}} 2+n_{\mathrm{D}} 2\right) k T,
$$

where $k=1.38 \cdot 10^{-23} \mathrm{~J} / \mathrm{K}$ is Boltzmann's constant; $p=3.92 \cdot 10^{11}$ is pressure, $\mathrm{Pa}$; $\mathrm{T}$ is temperature, $\mathrm{K}, n_{\mathrm{Fe}}$, $n_{\mathrm{H}}$ and $n_{\mathrm{D}}$ is respective nuclei concentrations of iron, hydrogen (protium and deuterium), $1 / \mathrm{m}^{3} ; i$ is degree of iron atoms ionization.

$\eta$ stands for the total relative content of protium and deuterium in plasma and is defined as

$$
\eta=\frac{n_{\mathrm{H}}+2 n_{\mathrm{D}}}{n_{\mathrm{Fe}} A_{\mathrm{Fe}}+n_{\mathrm{H}}+2 n_{\mathrm{D}}},
$$

where $A_{\mathrm{Fe}}=55.8$ is iron atomic weight. Share of deuterium in hydrogen is designated by $\delta$

$$
\delta=\frac{2 n_{\mathrm{D}}}{n_{\mathrm{H}}+2 n_{\mathrm{D}}} .
$$

At the considered temperatures, hydrogen atoms are fully ionized. The average ionization degree of iron atoms (during multiple ionization) is determined by Raizer approximation [27], which is simpler than Saha system of equations. We may write this equation as

$$
I(i+0.5)=k T \ln \left(\frac{2\left(\frac{2 \pi m_{e} k T}{h^{2}}\right)^{\frac{3}{2}}}{i n_{\mathrm{Fe}}+2 n_{\mathrm{H}}+2 n_{\mathrm{D}}}\right),
$$

where $I$ is ionization energy; $i$ is average ionization degree of iron atoms; $m_{e}$ is electron mass; $h$ is Planck constant.

Continuous function $I(i)$ is obtained by interpolation between energy levels of iron atoms multiple ioniza- 
tion described in [28]. In equation (4), the argument of function $I(i)$ is increased by 0.5 following the recommendation in [25].

Specific plasma volume is defined as

$$
V=\frac{1}{m_{\mathrm{H}}\left(A_{\mathrm{Fe}} n_{\mathrm{Fe}}+n_{\mathrm{H}}+2 n_{\mathrm{D}}\right)},
$$

where $m_{\mathrm{H}}$ is hydrogen atom mass.

The system of equations $(1-5)$ at the set values $\eta, \delta$, $p, I(i)$ allows defining numerically the following functions of temperature: $n_{\mathrm{Fe}}(T), n_{\mathrm{H}}(T), n_{\mathrm{D}}(T), i(T), V(T)$, i. e. to obtain the complete description of plasma parameters for the conditions under study.

The release of thermonuclear energy per mass unit is proportional to the square of deuterium nuclei concentration and depends on temperature in a complicated way. The corresponding formula is given in [28] and is written in SI units as

$$
q(T)=4.32 \cdot 10^{-28} \frac{n_{\mathrm{D}}^{2} \cdot V}{T^{\frac{2}{3}}} \exp \left(-\frac{4.25 \cdot 10^{3}}{T^{\frac{1}{3}}}\right),
$$

where $q$ is density of thermonuclear energy release per mass unit, $\mathrm{W} / \mathrm{kg}$.

Change in the plasma temperature depending on time is described by

$$
\frac{d T(t)}{d t}=\frac{q(T)}{C_{p}(T)},
$$

where $t$ is time; $C_{p}$ is specific thermal capacity of a mass unit under constant pressure.

Specific plasma thermal capacity in this case is a sum of four members

$$
\begin{gathered}
\left.C_{p}=\frac{3}{2} k\left[(i+1) n_{\mathrm{F}}+2 n_{\mathrm{H}}+2 n_{\mathrm{D}}\right)\right]+ \\
+I(i) n_{\mathrm{F}} V \frac{d i}{d T}+\frac{3}{2} k T n_{F} V \frac{d i}{d T}+p \frac{d V}{d T}
\end{gathered}
$$

where the first right member is thermal capacity of free particles, the second member - thermal capacity of electron detachment, the third member - thermal capacity of the detached electrons heating, the fourth member - thermal capacity of the plasma expansion (work counter the external pressure).

Total capacity $Q$ of energy release in thermonuclear core approximated in the plateau temperature profile is

$$
Q=\frac{4 \pi}{3} R \chi \frac{1}{V} q
$$

where $R$ is the Earth's radius; $\chi$ is the ratio between the thermonuclear core initial volume and the Earth's volume.

Expression (5) is approximate for non-stationary heat processes and temperature gradients.

The system of equations (1-9) allows obtaining numerical assessment in respect to the time of different plasma parameters and energy release of the thermonuclear core.

Fig. 4 presents estimated dependence of iron atoms ionization degree on temperature for $\eta=0.01 ; \delta=$ $=1.4 \cdot 10^{-4}$.

Fig. 5 shows estimated dependence of concentrations of deuterium, hydrogen and iron on temperature for $\eta=0.01 ; \delta=1.4 \cdot 10^{-4}$. When the temperature triples from 500 to $1500 \mathrm{kK}$, the plasma volume under suggested external pressure increases by more than three times (as would be true for the ideal gas). Additional volume increase (and density decrease) is explained by the multiple iron atoms ionization which occurs in this temperature range.

Fig. 6 presents estimated dependence of plasma density on temperature for $\eta=0.01 ; \delta=1.4 \cdot 10^{-4}$. In the studied temperature range $\geq 500 \mathrm{kK}$, plasma density is several time less than iron density in normal conditions, which allows treating the pressure as gas-kinetic (1).

Fig. 7 shows estimated relationship between the specific volume yield of thermonuclear energy in D-D reaction and temperature.

The data provided by Figs. 4-7 help to estimate the possible parameters of the Earth's thermonuclear core.

Fig. 8 presents the results of calculation of temperature-time relationship under different initial conditions.

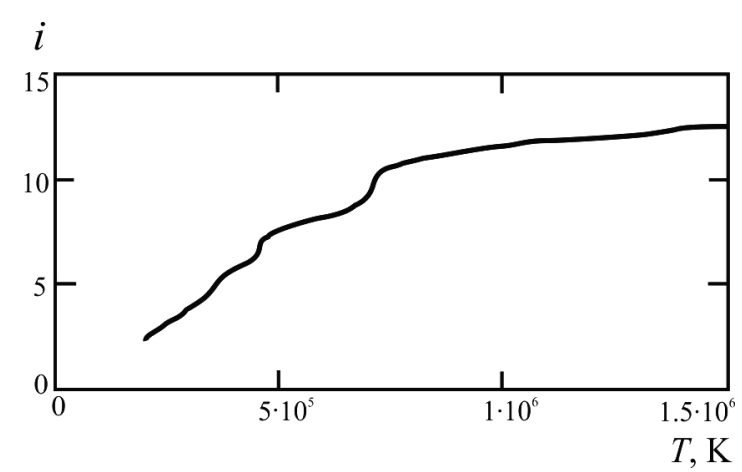

Fig. 4. Dependence of iron atoms ionization $i$ degree on temperature $T\left(\eta=0.01 ; \delta=1.4 \cdot 10^{-4}\right)$

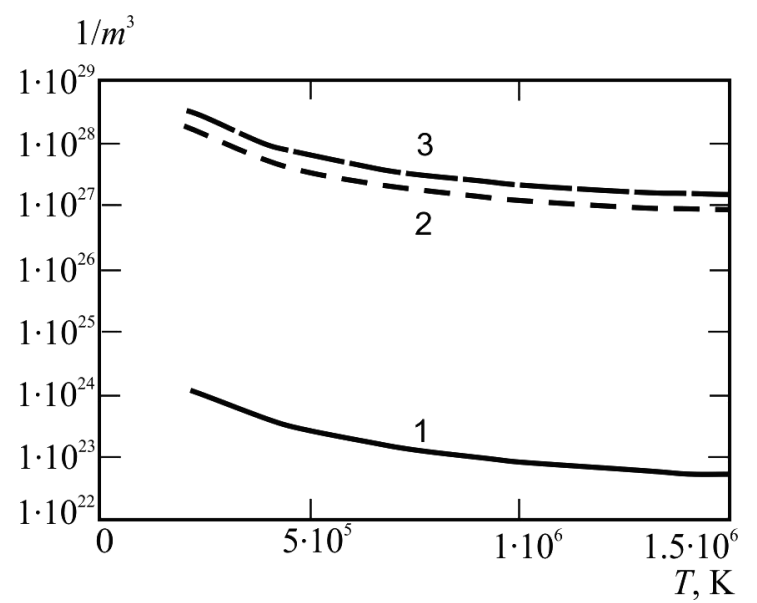

Fig. 5. Dependence of concentrations of deuterium (curve 1), hydrogen (curve 2) and iron (curve 3) on temperature $T\left(\eta=0.01 ; \delta=1.4 \cdot 10^{-4}\right)$ 


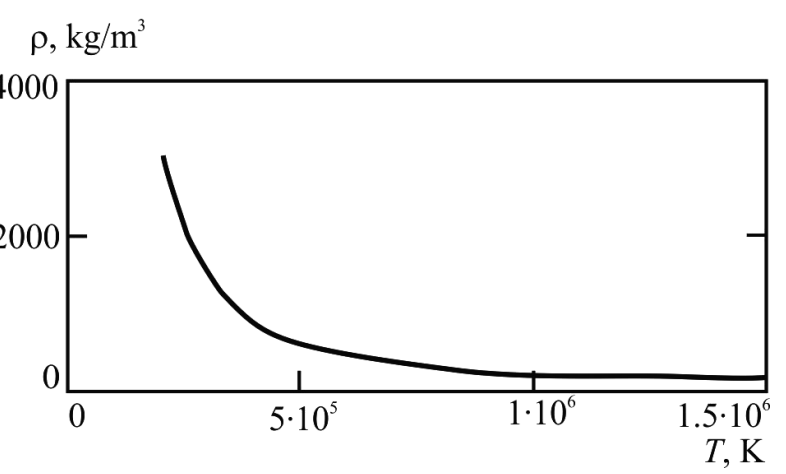

Fig. 6. Dependence of thermonuclear core plasma density $\rho$ on temperature $T\left(\eta=0.01 ; \delta=1.4 \cdot 10^{-4}\right)$

$q_{v}, \mathrm{~W} / \mathrm{m}^{3}$

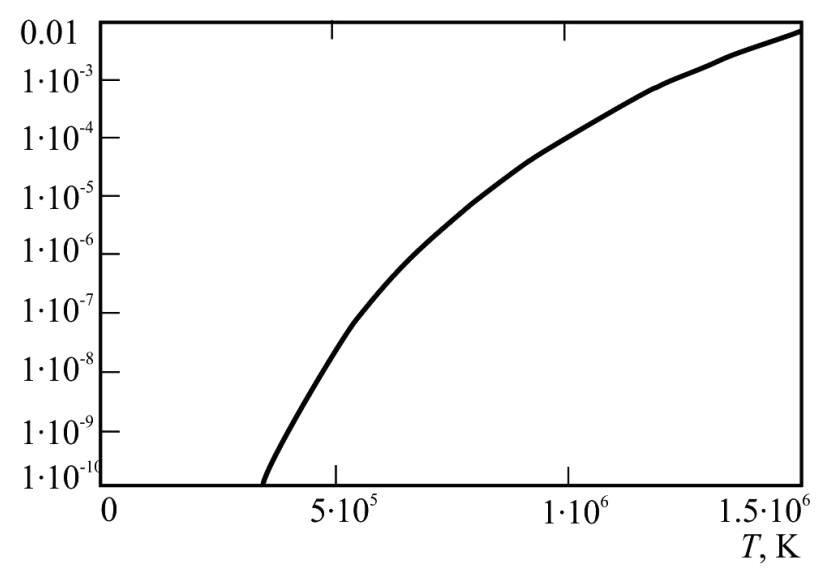

Fig. 7. Specific volume emission of thermonuclear energy in respect to temperature $\left(\eta=0.01 ; \delta=1.4 \cdot 10^{-4}\right)$

\section{$T, \mathrm{~K}$}

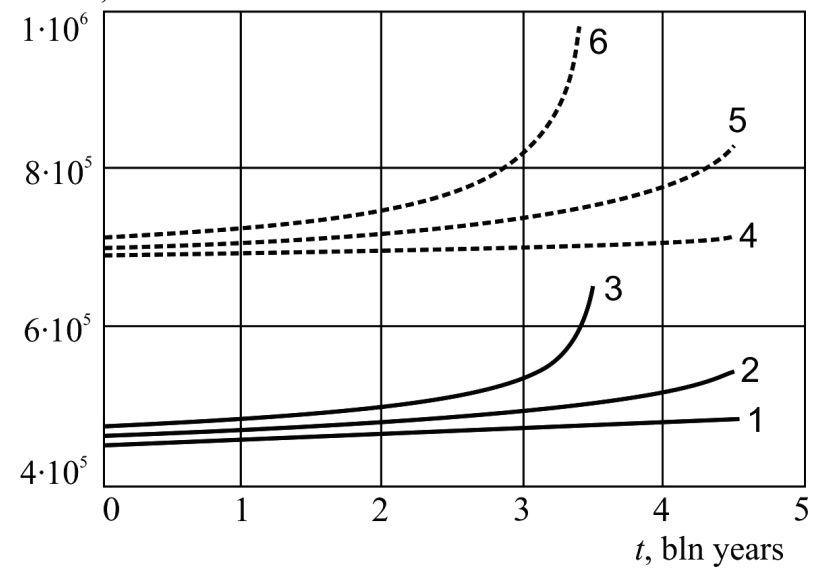

Fig. 8. Dependence of thermonuclear core temperature $T$ on time t. Curve numbers and the respective parameters $h$ and $T_{0}$ :

$1-h=1 ; T_{0}=450 \mathrm{kK} ; 2-h=1 ; T_{0}=460 \mathrm{kK} ; 3-h=1$; $T_{0}=470 \mathrm{kK} ; 4-h=0.01 ; T_{0}=690 \mathrm{kK} ; 5-h=0.01$; $T_{0}=700 \mathrm{kK} ; 6-h=0.01 ; T_{0}=710 \mathrm{kK}$

Curve numbers and the respective hydrogen content values, as well as the initial temperature are given below the Figure. The share of deuterium in hydrogen $\delta=$
$=1.4 \cdot 10^{-4}$. The initial relative volume of the thermonuclear core $\chi=10^{-3}$.

Curves $1-3$ show the temperature growth in respect to time for the case of the Earth's core made completely of hydrogen. Dashed curves 4-6 present the temperature growth for the case of iron-hydrogen thermonuclear core with the mass share of hydrogen $1 \%$. In both cases, mass share of deuterium in hydrogen is the same as on the Earth's surface $\delta=1.4 \cdot 10^{-4}$. There is a strong dependence of temperature growth on its initial value. In the case of the Earth's core made completely of hydrogen (curves $1-3$ ), if the initial temperature changes within $450 \ldots 470 \mathrm{kK}$, the trend of curves becomes qualitatively different in $\sim 3$ billion years. The same can be said about the case of iron-hydrogen Earth's core (curves 4-6) at much higher initial temperature in the range of $690 \ldots 710 \mathrm{kK}$. In both cases, after 3 billion years, the temperature growth becomes explosive, if the initial temperature corresponds to the upper boundary of the mentioned ranges. Dramatic growth of temperature is an expected consequence of the strong dependence of thermonuclear energy release on temperature 6 .

Fig. 9 presents the results of computing therelationship between the capacity of integral release of thermonuclear energy in the whole volume of the Earth's thermonuclear core and time under different initial conditions.

Let us estimate the actual range of initial temperatures that are necessary and possible for the formation of the Earth's thermonuclear plasma core on the basis of the data from Fig. 9 and the following argumentation. The lower boundary of the permissible initial temperatures range is determined by the fact that at such temperatures, emission of thermonuclear energy is lower than the observable heat flux from the depth of Earth. For the case of iron-hydrogen core $(\eta=0.01)$, this lower boundary is $\approx 690 \mathrm{kK}$, for completely hydrogen core $(\eta=1)-$ the lower boundary is $\approx 450 \mathrm{kK}$. The upper

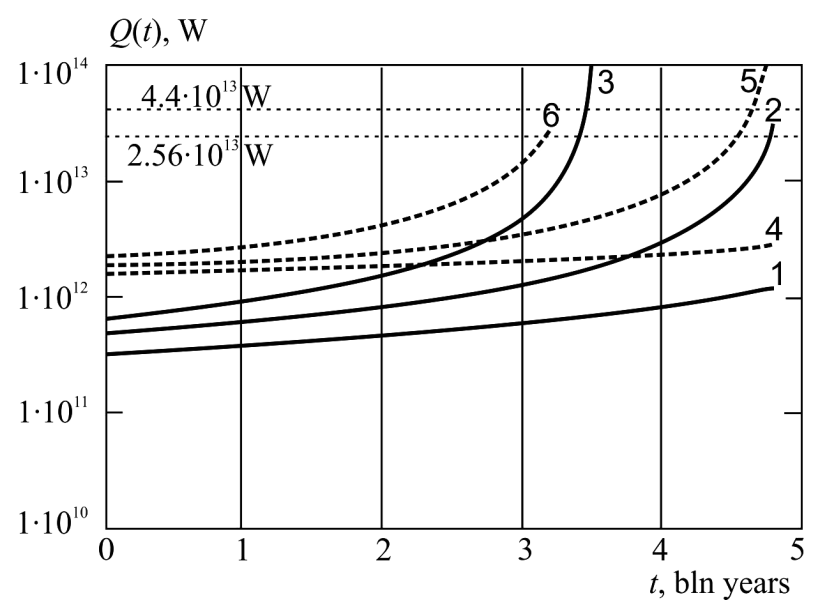

Fig. 9. Relationship between the capacity of energy released in thermonuclear core and time. Curve numbers and the respective parameters $h$ and $T_{0}$ :

$1-h=1 ; T_{0}=450 \mathrm{kK} ; 2-h=1 ; T_{0}=460 \mathrm{kK} ; 3-h=1 ;$ $T_{0}=470 \mathrm{kK} ; 4-h=0.01 ; T_{0}=690 \mathrm{kK} ; 5-h=0.01$; $T_{0}=700 \mathrm{kK} ; 6-h=0.01 ; T_{0}=710 \mathrm{kK}$ 
Computational values of the main thermonuclear core parameters

\begin{tabular}{|c|c|c|c|c|c|c|c|c|c|}
\hline \multirow[b]{2}{*}{ Parameters } & \multicolumn{3}{|c|}{ Nuclei concentration, $1 / \mathrm{m}^{3}$} & \multirow[b]{2}{*}{$\begin{array}{c}\text { Iron atoms } \\
\text { ionization } \\
\text { degree, } i\end{array}$} & \multicolumn{5}{|c|}{ Main thermonuclear core parameters } \\
\hline & $\begin{array}{c}\text { deuterium } \\
n_{D}\end{array}$ & $\begin{array}{c}\text { protium } \\
n_{H}\end{array}$ & $\begin{array}{l}\text { iron } \\
n_{\mathrm{Fe}}\end{array}$ & & 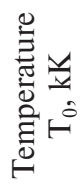 & $\begin{array}{c}\text { Specific volume } \\
\qquad, \mathrm{m}^{3} / \mathrm{kg}\end{array}$ & 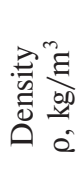 & 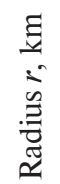 & $\begin{array}{c}\text { Energy release } \\
Q, \mathrm{~W}\end{array}$ \\
\hline Initial core & $1.35 \cdot 10^{23}$ & $1.91 \cdot 10^{27}$ & $3.42 \cdot 10^{27}$ & 9.74 & 700 & $3.11 \cdot 10^{-3}$ & 322 & 637 & $1.47 \cdot 10^{12}$ \\
\hline $\begin{array}{l}\text { After } 4.5 \text { billion } \\
\text { years }\end{array}$ & $1.03 \cdot 10^{23}$ & $1.48 \cdot 10^{27}$ & $2.62 \cdot 10^{27}$ & 10.97 & 829 & $4.06 \cdot 10^{-3}$ & 246 & 697 & $1.27 \cdot 10^{13}$ \\
\hline
\end{tabular}

boundary is determined by the fact that at high temperature, thermonuclear energy increases dramatically fast, i. e. the very fact of the Earth's existence during $\sim 5$ billion years allows estimating the upper boundary of the possible initial temperatures. For the iron-hydrogen core $(\eta=0.01)$ this upper boundary is $\approx 710 \mathrm{kK}$, for completely hydrogen core - the upper boundary is $\approx 470 \mathrm{kK}$. Unfortunately, the actual content of hydrogen in the core is not really known. Let us put together all the discussed information about the necessary and possible initial temperature of the Earth's thermonuclear plasma core. This brings us to the conclusion that for hydrogen content of $0.01<\eta<1$, the temperature is approximately within $450 \ldots 750 \mathrm{kK}$, with the average temperature of the range being $\sim 600 \mathrm{kK}$.

The Table below presents the results of calculating the evolution of the virtual Earth's thermonuclear core during the period of its existence for 4.5 billion years.

Conclusions. Heavy and light components in the interstellar vortex gas-and-dust cloud did not only mix but were also distributed in a regular way - the amount of heavy components increased with the distance from the rotation center to the vortex periphery. In the center of the large scale (stellar-planetary) vortex cloud, the lightest components (predominantly hydrogen and helium) were concentrated. After formation of the sun, which has taken the major part of light components from the central part of the cloud, the remaining mass of protosolar dust-and-gas cloud gives birth to planets and their satellites, containing mostly heavy components. However, emergence of local vortices in the arms of protoplanetary cloud results in the new differentiation of the matter, similar to that which had been before the Sun formation - predominantly light components and hydrogen before all concentrate in the center. Light components constitute the bulk of the central regions of the matter which forms the core of the future planet. The regular distribution of components in vortices in terms of mass significantly increases the probability of the planet's "light" core formation.

The research offers one of the probable mechanisms for the formation of initially "light" Earth's core and provides the results of the theoretical assessment of thermonuclear core major physical parameters during 4.5 billion years. Hence it is noteworthy that experimental data of the complete heat flux value through the
Earth surface and the estimated values of the emitted heat related to time are very close.

Mechanical quasi-stability of the Earth as a physical system (light core, heavy components in the mantle and mostly in the crust) initially established is the reason for periodic activation of different geological processes. Such activation is accompanied by reorganization of the inner structure which is aimed on the whole at the planet's transition to the equilibrium state. Such scenario of the Earth's evolution can testify to the fact that the reduction of inner energy store and the natural attenuation of internal physical and chemical processes activity will be accompanied by the extinction of life on the planet. In other words, manifestations of the planet's (or star's) physical, mechanical or chemical stability testify to its perishing.

The authors have estimated the main conditions necessary for thermonuclear heating of the Earth's central regions; concentration of deuterium nuclei and the range of the necessary initial temperatures. The changes in plasma parameters and thermonuclear energy release have been determined in respect to time.

\section{References.}

1. Kuznetsov, V. V., 1997. The anisotropy of properties of the Earth's inner core. Phys. Usp., 40:9, pp. 951-961. DOI: $10.3367 /$ UFNr.0167.199709e.1001.

2. Shilo, N.A., 1982. On the mechanism of formation of the solar system. Tikhookean. Geology, 6. pp. 20-27.

3. Wohlers, A. and Wood, B. J., 2015. A Mercury-like component of early Earth yields uranium in the core and high mantle ${ }^{142} \mathrm{Nd}$. Nature, 520, pp. 337-340. DOI:10.1038/nature14350.

4. Anisichkin, V.F., Ershov, A.P., Bezborodov, A.A. and Suslov, I. R., 2003. The possible modes of chain nuclear reactions in the Earth's core. In: Int. Conf. "VII Zababakhin's Sientific Lectures”, Snezhinsk, Russia, 8-12 September [online], pp. 1-9. Available at: <http:// www.vniitf.ru/rig/konfer/7zst/reports/s1/s-1.htm> [Accessed 19 August 2017].

5. Larin, V. N., 2005. Our Earth. Moscow: Agar [online]. Available at: $<$ http://hydrogen-future.com/list-clarin/14-earth.html $>$ [Accessed 24 September 2017].

6. Gilat, A. and Vol, A., 2012. Degassing of primordial hydrogen and helium as the major energy source for internal terrestrial processes. Geoscience Frontiers, 3(6), pp. 911-921. DOI: 10.1016/j.gsf.2012.03.009. 
7. Shilo, N.A., 1988. Vortices - the cradle of the Solar system. In: Hypotheses: predictions: the future of science: an international yearbook. Moscow: Znanie, 21, pp. 89-111. 8. Litasov, K. D. and Shatskiy, A. F., 2016. Composition of the Earth's core: A review. Russian Geology and Geophysics, 57(1), pp. 22-46. DOI: 10.15372/GiG20160103. 9. Kuznetsov, V. V., 2008. Introduction to the physics of hot Earth. Kamchatka, Paratunka: IKIR [pdf]. Available at: <http://www.geokniga.org/bookfiles/geoknigavvedenie-v-fiziku-goryachey-zemli.pdf $>$ [Accessed 11 September 2017].

10. Pushcharovsky, D. Yu. and Pushcharovsky, Yu. M., 1998. Composition and structure of the earth's mantle. Soros Educational Journal [pdf], 11, pp. 111-119. Available at: <http://www.pereplet.ru/nauka/Soros/pdf/ 9811_111.pdf $>$ [Accessed 5 June 2017].

11. Shumakova, T.A. and Berczik, P. P., 2005. Chemical radial gradient evolution in the disk of a massive galaxy due to its minor merger with a dwarf galaxy. Kinematics and physics of celestial bodies [online], 21(4), pp. 288303. Available at: <http://dspace.nbuv.gov.ua/handle/123456789/79143> [Accessed 10 September 2017].

12. Sobolev, V. V., 1987. Shock-wave separation of chemical compounds and mixtures of materials into components. Mineral Processing, 7, pp. 63-68.

13. Sobolev, V.V., 1984. Origin of spiral vortices in mixed cylindrical samples under shock compression. Technical Physics Letters, 10(8), pp. 459-463.

14. Sobolev, V. and Hove, I. H., 1997. Phenomenon of Spiral Vortex Formation Over the Shock Wave Front. Journal De Physique. IV. Colloque, 7(C.3), pp. 127-129. DOI: 10.1051/jp4:1997324.

15. Chernai, A. V., Sobolev, V. V., Ilyushin, M.A. and Zhitnik, N.E., 1994. Generating mechanical pulses by the laser blasting of explosive coatings. Combustion, Explosion, and Shock Waves, 30(239), pp. 239-242. DOI: 10.1007/BF00786134.

16. Didyk, R.P., Sobolev, V.V., Gryaznova, L. V. and Pikar S. N., 1977. On the possible nature of the flows of matter in cylindrical ampoules under shock compression. In: Synthesis and investigation of properties of superhard materials. Kiev: ISM, pp. 91-94.

17. Voitenko, A. Ye., 2007. Etude of thermonuclear heating of the central region of the Earth. In: Physics and Technology of high-energy material processing. Dnepropetrovsk: ART-PRESS. pp. 62-70.

18. Gurevich, L. E. and Chernin, A. D., 1978. Introduction to cosmogony. The origin of the large-scale structure of the universe. Moscow: Nauka.

19. Terez, E. I. and Terez, I. E., 2011. Thermonuclear processes in the core is the main source of energy of geodynamic evolution and degassing of the Earth. Bulletin of the Crimean Astrophysical Observatory, 107(1), pp. 152-164. DOI: 10.3103/S0190271711010153.

20. Fukuhara, M., 2016. Possible generation of heat from nuclear fusion in Earth's inner core. Sci. Rep. 6, 37740. DOI: 10.1038 / srep37740.

21. Zharkov, V.N., 2013. Interior Structure of the Earth and Planets. Moscow: Nauka i obrazovanie [pdf]. Available at: <http://ocean.phys.msu.ru/courses/geo/lib/ books/Жарков\%20Внутреннее\% 20строение\% 20
Земли\%20и\%20планет.pdf> [Accessed 27 October 2017].

22. Herndon, J. M., 1992. Nuclear fission reactors as energy sources for the giant outer planets. Naturwissenschaften, 79(1), pp. 7-14. DOI: 10.1007/ BF01132272.

23. Terez, E. I. and Terez, I. E., 2015. Synthesis reactions - the main source of internal energy of the Earth. Herald of the Russian Academy of Sciences, 85(3), pp. 240-246. DOI: 10.7868/S0869587315030172.

24. Anderson, Don L., 2007. New Theory of the Earth. Cambridge University Press, New York [online]. Available at: <http://resolver.caltech.edu/CaltechBOOK: 2007.001> [Accessed 5 June 2017].

25. Pollak, H. N., Hurter, S. J. and Johnson, J. R., 1993. Heat Flow from the Earth's Interior: Analysis of the Global Data Set. Reviews of Geophysics, 3, pp. 267-280. DOI: 10.1029/93RG01249.

26. Lay, T., Hernlund, J. and Buffet, B. A., 2008. Coremantle boundary heat flow. Nature Geoscience, 1, pp. 25-35. DOI:10.1038/ngeo.2007.44.

27. Zel'dovich, Ya. B. and Raizer, Yu. P., 2008. Physics of Shock Waves and High-Temperature Hydrodynamic Phenomena. Moscow: FIZMATLIT [pdf]. Available at: $<$ http://master.basnet.by/bfo/zeld/2.pdf> [Accessed 1 November 2017].

28. Artsimovich, L.A., 1961. Controlled Thermonuclear Reactions. Moscow: Fizmatgis [online]. Available at: <https://www.twirpx.com/file/910411/> [Accessed 4 June 2017].

\section{Фізичні умови утворення ,легкого“ ядра та термоядерне джерело тепла в надрах землі}

\author{
В. В. Соболєв, Н. В. Білан
}

Державний вищий навчальний заклад „Національний гірничий університет“, м. Дніпро, Україна, е-mail: velo1947@ukr.net

Мета. Експериментальні дослідження фізичної моделі утворення ядра Землі в центрі газопилового спірального вихору й чисельні оцінки фізичних умов для розвитку термоядерних реакцій в ядрі Землі.

Методика. Аналіз сутності використовуваних концепцій та основних достоїнств і недоліків, що визначають їх потенційні можливості. Експериментальні дослідження із застосуванням ударнохвильової обробки пористих матеріалів у циліндричних контейнерах. Чисельні оцінки фізичних умов в ядрі Землі, що ініціюють термоядерні реакціі.

Результати. Вибір моделі формування Землі 3 вихідним ,легким“ ядром є принципово важливим із кількох причин. По-перше, дає фізично обгрунтований механізм утворення термоядерного джерела тепла, а, по-друге, процес переходу Землі до рівноважного стану неминуче створює умови для механічної та фізико-хімічної активності елементів у геосфері. Проведена кількісна оцінка головних умов, необхідних для термоядерного нагріву цен- 
тральних областей Землі, а саме, концентрації ядер дейтерію й необхідних температур.

Наукова новизна. Запропонована модель формування вихідного „легкого“ ядра Землі. Експериментально досліджені деякі фізичні особливості зародження й розвитку спіральних вихорів. Встановлені закономірності зміни параметрів плазми, температури ядра й виділення термоядерної енергії в залежності від зміни віку Землі.

Практична значимість. Отримані результати можуть бути корисні при вивченні таких найважливіших планетарних геологічних явищ як диференціація речовини та утворення сфер усередині планети, а також розподіл теплових потоків в її надрах.

Ключові слова: газопилова речовина, спіральний вихор, ядро Землі, термоядерні реакції, вік Землі

\section{Физические условия образования „легкого“ ядра и термоядерный источник тепла в недрах земли}

\section{В. В. Соболев, Н. В. Билан}

Государственное высшее учебное заведение „Национальный горный университет“, г. Днепр, Украина, e-mail: velo1947@ukr.net

Цель. Экспериментальные исследования физической модели образования ядра Земли в центре газопылевого спирального вихря и численные оценки физических условий для развития термоядерных реакций в ядре Земли.

Методика. Анализ сущности используемых концепций и основных достоинств и недостатков, определяющих их потенциальные возможности. Экспериментальные исследования с применением ударно-волновой обработки пористых материалов в цилиндрических контейнерах. Численные оценки физических условий в ядре Земли, инициирующих термоядерные реакции.

Результаты. Выбор модели формирования Земли с изначально „легким“ ядром является принципиально важным по нескольким причинам. Вопервых, дает физически обоснованный механизм образования термоядерного источника тепла, а, вовторых, процесс перехода Земли к равновесному состоянию неизбежно создает условия для механической и физико-химической активности элементов в геосферах. Проведена численная оценка главных условий, необходимых для термоядерного нагрева центральных областей Земли, а именно, концентрации ядер дейтерия и необходимых температур.

Научная новизна. Предложена модель формирования изначально „легкого“ ядра Земли. Экспериментально исследованы некоторые физические особенности зарождения и развития спиральных вихрей. Установлены закономерности изменения параметров плазмы, температуры ядра и выделения термоядерной энергии в зависимости от изменения возраста Земли.

Практическая значимость. Полученные результаты могут быть полезны при изучении таких важнейших планетарных геологических явлений как дифференциация вещества и образование сфер внутри планеты, а также распределение тепловых потоков в ее недрах.

Ключевые слова: газопылевое вещество, спиральный вихрь, ядро Земли, термоядерные реакции, возраст Земли

Рекомендовано до публікації докт. техн. наук М.М.Довбнічем. Дата надходження рукопису 18.08.17. 